\title{
AN APPROACH FOR TRAFFIC COLLISION AVOIDANCE: MEASURING THE SIMILAR EVIDENCE ON THE CAUSAL FACTORS OF COLLISIONS
}

\author{
Liangguo $\mathrm{KANG}^{1,2^{*}}$, Shuli $\mathrm{ZHANG}^{1,3}$, Chao $\mathrm{WU}^{1,2^{\#}}$ \\ ${ }^{1}$ School of Resources and Safety Engineering, Central South University, Changsha, China \\ ${ }^{2}$ Safety and Security Theory Innovation and Promotion Center, Central South University, Changsha, China \\ ${ }^{3}$ Taiyuan Municipal Public Utilities Administration, Taiyuan, China
}

Submitted 6 December 2019; resubmitted 1 April 2020, 7 July 2020; accepted 27 July 2020;

first published online 17 March 2021

\begin{abstract}
The lessons learned from each Traffic Collision (TC) will help safety practitioners to avoid similar occurrences in the future. However, few studies and methods have focused specifically on the similar features among different collisions. Thus, the development of a measurement method for investigating the best evidence on the causal factors of TCs was warranted. In this study, a similarity analysis method based on the Analytic Hierarchy Process (AHP) and Similarity (S) theory, the AHP-S method, was constructed. This method was designed to identify the similar elements and similar units of collision scenes according to the analysis criteria and sub-criteria and further to calculate the degree of similarity between recognized similar pairs among TCs. Six TC cases were randomly selected as examples, and the degrees of similarity between cases 1 to 5 and case 6 were calculated separately. The calculation results showed that out of the five collision cases (cases $1-5$ ), case 1 provided the best evidence for analysing the causal factors of case 6 . This study promotes the development of quantitative analysis methods for collision incidents and provides an effective evidence-based method for TC avoidance.
\end{abstract}

Keywords: traffic collision, causal factors, similarity analysis, similar evidence, collision analysis.

\section{Notations}

AHP - analytic hierarchy process;

AHP-S - AHP with similarity theory;

$\mathrm{CI}$ - consistency index;

CR - consistency ratio;

$\mathrm{RI}$ - random index;

TC - traffic collision.

\section{Introduction}

TCs are a global problem and primary concern in the 21 st century. Globally, the number of fatalities resulting from TCs is 1.25 million per year (Pérez et al. 2019). In the US, there are approximately 33000 traffic fatalities per year (Wu et al. 2013). In Europe, 26009 people were killed as a result of TCs in 2013 in the 28 EU countries (Chen et al. 2016). In Australia and New Zealand, respectively, 31 and $16 \%$ of fatal occupational incidents are TCs (Nævestad et al. 2015). In Great Britain, over the period 2004 to 2013, the average annual number of road fatalities was 2452 (Sarkar et al. 2018). Road safety is an issue that needs to be solved urgently in China, where 57277 people were killed in TCs in 2012 (Chen et al. 2015; Zhao, Deng 2015). Accordingly, safety countermeasures based on information sources related to such incidents should be taken to decrease the number of traffic fatalities and injuries. Causal analysis is one of the basic ways to study TCs and to discover the weaknesses of traffic safety measures. Under the circumstances, understanding the various factors that cause TCs is crucial.

Empirical research has identified a large number of factors related to TCs. The occurrence of TCs is usually related to human, vehicle, road, environment, and management factors (Prentkovskis et al. 2010; Podvezko, Sivilevičius 2013; Chen et al. 2015; Cvitanić, Vukoje 2018; Sze, Song 2019). Among the human factors, speeding or driver negligence are the main causes of TCs (Goel, Sachdeva 2016), and approximately $20 \%$ of TCs worldwide are related to driver fatigue (MacLean et al. 2003; Fernandes et al. 2010). Chen et al. (2004) found that 4.94\% of collisions are caused by vehicle factors. Regarding road factors, creating reasonable traffic facilities could reduce the TC rate ( $\mathrm{Hu}, \mathrm{Li} 2014)$. With respect to environment factors, the number of TCs is significantly affected by weather variables: for example, the risk of a collision

${ }^{*}$ Corresponding author. E-mail: kangliangguo@126.com

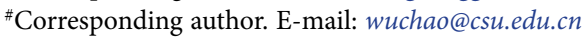


increases if the precipitation is falling as snow (Andersson, Chapman 2011). However, these factors are not fully independent of each other, and each factor is influenced by many other factors and indicators (Chen et al. 2015).

Learning from past incidents is fundamental to incident prevention (Goh, Ubeynarayana 2017). A good way to gain safety insights from collisions is through similarity analysis, which can create an overall evaluation indicator to calculate the degree of similarity between different collisions. This calculation model is based on a wide literature review, which involves five types of factors: human, vehicle, road, environment, and management. Currently, there are two major types of operations research methods in terms of indicator aggregating, namely, data envelopment analysis and multiple-criteria decision analysis (Zhou, Ang 2009). These two methods are commonly used to evaluate road safety performance for a set of decision-making units (Chen et al. 2015). The AHP has been used in nearly all applications related to multiple-criteria decision analysis (Hruška et al. 2014; Stević et al. 2019). In the AHP, factors related to a decision-making issue are categorized and then formed into a hierarchy (Ilbahar et al. 2018). The application of the AHP has become common practice in road safety to evaluate and determine the importance weightings of indicators or criteria (Duleba 2019; Farooq et al. 2019). However, due to the lack of a computational procedure to assess degree of similarity, it is not enough to only use the AHP method for analysing the causal factors of collisions. Currently, there are no methods available to investigate similar evidence in relation to the causal factors of collisions. Thus, it is worthwhile exploring and testing new methods to make up for this deficiency. In this study, we constructed a similarity analysis method, the AHP-S method, that can be considered as a natural extension of the two basic methods, the AHP and Similarity (S) theory, and be used to compute the degree of similarity between the causal factors of TCs.

The contributions of this study are as follows:

"») the introduction of a new method for analysing the degree of similarity between different collisions by considering both the causal factors of TCs and existing collision information sources;

"» an analysis of the degree of similarity of six TC cases, which could help to clarify the application process of similarity analysis for international readers;

"» the discovery of the weak aspects of traffic safety, which can help the decision maker to develop targeted measures that would lessen or avoid the occurrence of collisions.

\section{Methodologies}

\subsection{Mathematical method of similarity analysis}

The core work of this section introduces the method we developed for computing the degree of similarity between TCs. This method combines the advantages of the AHP and Similarity (S) theory, and so we named it the AHP-S method. The AHP has been widely applied to solve complex multiple-criteria problems by structuring them into a hierarchy (Ho, Ma 2018). The overall decision-making goal is placed at the top of the hierarchy, with lower levels of criteria and alternatives placed below. Each criterion or sub-criterion can be further divided into appropriate levels of detail, and decision alternatives are laid down at the last level of the hierarchy (Calabrese et al. 2016). Similarity theory is widely used to provide evidence-based practice support for safety practitioners, but it can only qualitatively analyse the similar features of TCs. Currently, similarity theory lacks a suitable quantitative description for analysing the degree of similarity between incidents, and thus there is a need to construct computational procedures. In this context, we developed a similarity analysis method (i.e., AHP-S method) for investigating the best evidence on the causal factors of TCs. The computational procedure of similarity analysis is as follows.

\subsubsection{The relative weight $w_{i}$}

To obtain the degree of importance of similar units, a structure is established which takes the criteria as the target level, the sub-criteria as the middle level, and the similar units as the bottom level (Figure 1).

The relative importance of two similar units is established on the basis of Saaty's Fundamental Scale (Herva, Roca 2013), which consists of nine possible numeric values. Table 1 provides descriptions of each degree of the scale.

The comparison of two similar units $\left(u_{i}, u_{j}\right)$ can be mathematically presented as:

$$
S_{i j}=\frac{u_{i}}{u_{j}}(i, j=1,2,3, \ldots, k),
$$

where: $S_{i j}$ denotes the weight exchange value of the pairwise comparison of $u_{i}$ and $u_{j}$ (Table 2).

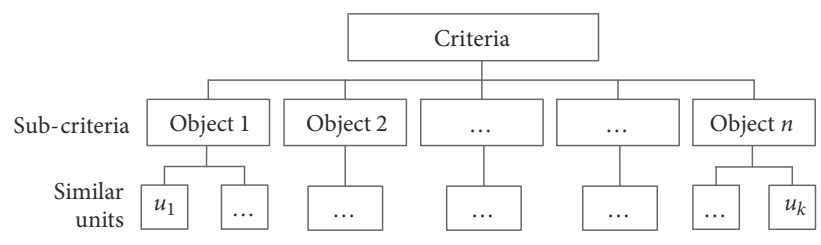

Figure 1. Structure for analysing the importance of similar units

Table 1. Pair-wise comparison scale (Saaty 2008)

\begin{tabular}{|l|l|}
\hline \multicolumn{1}{|c|}{$\begin{array}{c}\text { Intensity of } \\
\text { importance }\end{array}$} & \multicolumn{1}{c|}{ Definition } \\
\hline 1 & equal importance \\
\hline 3 & moderate importance \\
\hline 5 & essential or strong importance \\
\hline 7 & very strong importance \\
\hline 9 & extreme importance \\
\hline $2,4,6,8$ & $\begin{array}{l}\text { intermediate values between the two } \\
\text { adjacent judgments }\end{array}$ \\
\hline
\end{tabular}


Table 2. Pair-wise comparison matrix for similar units

\begin{tabular}{|c:ccccc|}
\hline$S$ & $u_{1}$ & $\ldots$ & $u_{j}$ & $\ldots$ & $u_{k}$ \\
\hdashline$u_{1}$ & $s_{11}$ & $\ldots$ & $s_{1 j}$ & $\ldots$ & $s_{1 k}$ \\
$\ldots$ & $\ldots$ & $\ldots$ & $\ldots$ & $\ldots$ & $\ldots$ \\
$u_{i}$ & $s_{i 1}$ & $\ldots$ & $s_{i j}$ & $\ldots$ & $s_{i k}$ \\
$\ldots$ & $\ldots$ & $\ldots$ & $\ldots$ & $\ldots$ & $\ldots$ \\
$u_{k}$ & $s_{k 1}$ & $\ldots$ & $s_{k j}$ & $\ldots$ & $s_{k k}$ \\
\hline
\end{tabular}

$S_{i j}=1$ means that $u_{i}$ is equally as important as $u_{j}$, and $S_{i j}=9$ means that $u_{i}$ is extremely more important than $u_{j}$. Odd degrees are usually used for judgments, and even degrees $(2,4,6$, and 8$)$ are used if the decision maker is unable to make an explicit assessment between two judgments. The determination of similar units is based on the axiom of reciprocity. If the decision maker considers that $u_{i}$ is moderately more important than $u_{j}\left(u_{i}=3 \cdot u_{j}\right.$, i.e., $S_{i j}=3$ ), then $u_{j}$ will be three times weaker than $u_{i}$ $\left(u_{j}=1 / 3 \cdot u_{i}\right.$, i.e., $\left.S_{j i}=1 / 3\right)$. The matrix $S$ can be mathematically presented as:

$$
S=\left[\begin{array}{ccccc}
s_{11} & \ldots & s_{1 j} & \ldots & s_{1 k} \\
\ldots & \ldots & \ldots & \ldots & \ldots \\
s_{i 1} & \ldots & s_{i j} & \ldots & s_{i k} \\
\ldots & \ldots & \ldots & \ldots & \ldots \\
s_{k 1} & \ldots & s_{k j} & \ldots & s_{k k}
\end{array}\right] .
$$

By normalizing the solution, the relative weight $w_{i}$ can be mathematically presented as:

$$
w_{i}=\frac{1}{k} \cdot \sum_{j=1}^{k} \frac{s_{i j}}{\sum_{c=1}^{k} s_{c j}} \text {. }
$$

The maximum eigenvalue $\lambda_{\max }$ equals the number of orders. It can be presented as follows:

$$
\lambda_{\max }=\frac{1}{k} \cdot \sum_{i=1}^{k} \frac{\left(S \cdot w_{i}\right)}{w_{i}}
$$

If $S$ is a consistent matrix, then the maximum eigenvalue of $S$ is equal to its number of orders. However, the pair-wise comparison matrix cannot achieve complete consistency in practice. The difference in value between $\lambda_{\max }$ and $k$ can be used to judge the degree of consistency. The CI can be calculated as follows:

$$
C I=\frac{\lambda_{\max }-k}{k-1} \text {. }
$$

For each comparison matrix, a corresponding RI is used. RI is an index of a randomly generated reciprocal matrix. Its values for computation purposes are presented in Table 3.

To check the correctness of comparisons, a CR is designated. It is calculated to determine the inconsistency in the evaluation. It is determined in accordance with the following equation:

$$
C R=\frac{C I}{R I} \text {. }
$$

Table 3. Average consistency values of random matrices

\begin{tabular}{|c|c|c|c|c|c|c|c|c|c|c|c|c|}
\hline$k$ & 1 & 2 & 3 & 4 & 5 & 6 & 7 & 8 & 9 & 10 & 11 & 12 \\
\hline$R I$ & 0 & 0 & 0.52 & 0.89 & 1.12 & 1.24 & 1.36 & 1.41 & 1.46 & 1.49 & 1.52 & 1.54 \\
\hline
\end{tabular}

Table 4. Pair-wise similarity scale

\begin{tabular}{|l|l|}
\hline \multicolumn{1}{|c|}{ Degree of similarity } & \multicolumn{1}{c|}{ Definition } \\
\hline 0.1 & slight similarity \\
\hline 0.3 & moderate similarity \\
\hline 0.5 & essential or strong similarity \\
\hline 0.7 & very strong similarity \\
\hline 0.9 & extreme similarity \\
\hline $0.2,0.4,0.6,0.8$ & $\begin{array}{l}\text { intermediate values between } \\
\text { the two adjacent judgments }\end{array}$ \\
\hline
\end{tabular}

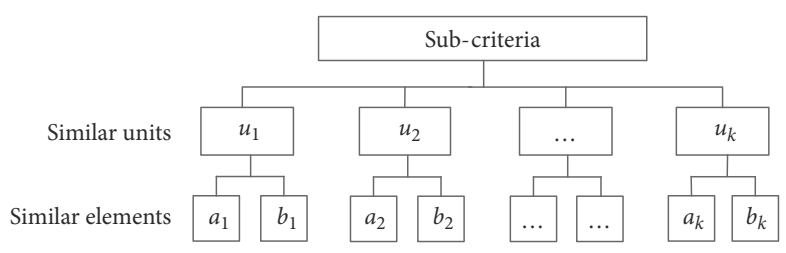

Figure 2. Structure for analysing the values of similar units

If $C R \leq 0.1$, it means that the evaluation within the matrix is acceptable. Otherwise, the judgments are untrustworthy.

\subsubsection{The values of similar units $q_{i}$}

A structure is constructed to obtain the values of similar units by means of similarity theory, which takes sub-criteria as the target level, similar units as the middle level, and similar elements as the bottom level (Figure 2).

It assumes that case I involves $m$ elements (denoted by $a$ ) and case II involves $n$ elements (denoted by $b$ ). The number of similar units between case I and II is $k$, which may be mathematically presented as:

$$
k=m \cap n,
$$

where: $a_{i}, b_{i}$ denote similar elements; $u_{i}$ denotes a similar unit formed by $a_{i}$ and $b_{i} ; q_{i}$ denotes the degree of similarity between $a_{i}$ and $b_{i}$, i.e., the values of $u_{i}(i=1,2,3, \ldots, k)$. Also, $q_{i}$ within 0 to 1 are selected. $q_{i}=0$ means that $a_{i}$ is totally different from $b_{i}$, and $q_{i}=1$ means that $a_{i}$ is the same as $b_{i}$. The degrees $0.1,0.3,0.5,0.7$, and 0.9 are usually used, and the degrees $0.2,0.4,0.6$, and 0.8 are used if it is not possible for the decision maker to make an explicit assessment (Table 4). $q_{i}=0.7$ means that there is very strong similarity between $a_{i}$ and $b_{i}$, which indicates that the decision maker assessed the degree of similarity between two elements to be very strong.

\subsubsection{The degree of similarity $Q(I, I I)$}

According to the relative weight $w_{i}$ and the values of similar units $q_{i}$, the degree of similarity between case I and 
case II, i.e., $Q(I, I I)$, is calculated as follows:

$$
Q(I, I I)=\frac{k}{m+n-k} \cdot \sum_{i=1}^{k} w_{i} \cdot q_{i} .
$$

Case I will provide the best evidence available for analysis in case II when $Q(I, I I)$ is close to 1 . Otherwise, it cannot provide evidence for analysis in case II.

\subsection{Research process of similarity analysis}

Similarity analysis of the causal factors of TCs can be realized by using the principle of "similarity safety systematics" (Wu, Jia 2016; Jia et al. 2016), which is intended to analyse the degree of similarity between collisions. As the large number of traffic cases provides a practical basis for analysis, similarity analysis of collisions is one of the important tools that can be used to avoid similar occurrences by using the data and detailed information on recorded collisions. Similarity analysis has the following advantages:

"» it makes up for the shortcomings of the traditional frequency analysis of collisions;

"'» it provides the decision maker with effective evidence by calculating the degree of similarity between the causal factors of TCs;

"») it enables safety countermeasures based on current incident information sources to be taken to improve traffic safety practices.

Similarity analysis investigates the similar features of study objects, thus providing evidence-based information for safety practices (Wang et al. 2017). Taking TCs as an example, the research process of similarity analysis is as follows (Figure 3):

"» TC cases are selected according to the research objectives;

"») the decision maker sets specific criteria and subcriteria of TCs: e.g., criteria are set as driver factors, and sub-criteria are set as driver's behaviour, decision-making ability, and reaction speed;

"» the similar elements of TCs are identified: e.g., the similar elements of a causal factor are identified by the criteria and sub-criteria, and then the degree of similarity between similar elements is analysed in a mathematical way;

"» the similar units of TCs are analysed: e.g., similar units are identified by means of the elements of different cases; then, the decision maker mathematically compares the relative importance of the similar units;

"»" the degree of similarity between case $I$ and case $I I$ is calculated under the condition of $0 \leq Q(I, I I) \leq 1$;

"»» the decision maker applies the results to improve traffic safety practices.

\section{Application of proposed method}

\subsection{TC case selection}

There were approximately 960000 TCs in China over the period 2012 to 2016; among these, 68 were major accident level or above. The term major accident level or above refers to an accident that results in over 10 deaths or over 50 serious injuries or in direct economic losses of over 50 million CNY (SC PRC 2007). Information on collisions was obtained from the accident investigation reports of the State Administration of Work Safety (SAWS 2016) of China as well as related studies by Li and Xiao (2016a, 2016b, 2016c, 2016d, 2016e, 2017). The 68 cases were classified as follows: 16 head-on crashes, 6 rear-end crashes, 38 overturns, 3 fires, and 5 others. Six cases were randomly selected from among the 16 head-on crashes to analyse the degree of similarity between the causal factors of TCs (Table 5).

\subsection{Criteria and sub-criteria of TCs}

TCs are among the leading causes of death and injuries of various levels in China (Chen et al. 2015). The key focus of similarity analysis is to investigate the cause of collisions on the basis of current collision information sources. Llopis-Castelló et al. (2018) proposed that the most important factors in the occurrence of road crashes are related to infrastructure, vehicle, and human factors. Lum and Reagan (1995) studied crash reports in the US, which showed that collisions are due to the roadway conditions, drivers, and vehicles and the interaction among several factors. Chen et al. (2004) analysed the causes of TCs in China across 2000; their analysis indicated that collisions are caused by human, vehicle, road, and environment factors. The findings indicate that road safety is a complex system issue comprising five types of factors (human, vehicle, road, environment, and management) and that TCs can be caused by a single factor or a combination of these five factors (Chen et al. 2015). The relationship among the five factors is illustrated in Figure 4.

The causal factors of TCs can be divided into internal factors (management) and external factors (human, vehicle, road, and environment), and these factors contain similar elements:

"» the causal factors of TCs mutually affect one another and are connected: for instance, poor weather (e.g., rainy weather) has a great influence on driver's sight, which increases the probability of a collision occurring;

"» the causes of TCs mainly consist of one or several factors: for instance, human factors (e.g., drinkdriving) may be the main cause of a TC even if environment, vehicle, and road conditions are normal;

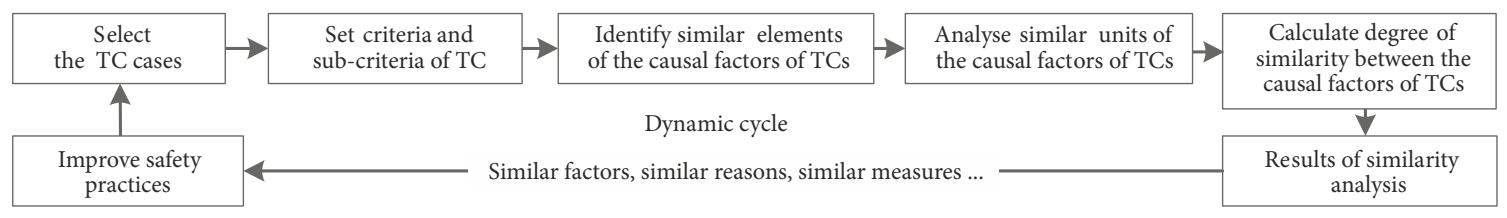

Figure 3. Research process of a similarity analysis of TCs 
Table 5. A brief introduction to six TC cases in China

\begin{tabular}{|c|c|}
\hline Case & A brief introduction \\
\hline 1 & $\begin{array}{l}\text { On } 23 \text { April 2012, Cao was driving a heavy truck. He crossed the double yellow lines in the center of the highway, rushing } \\
\text { into the opposite lane. Then, at } 132 \mathrm{~km}+500 \mathrm{~m} \text { on provincial highway } 220 \text { in China, the truck collided with a medium- } \\
\text { sized bus driven by Gao. The incident resulted in } 14 \text { deaths, } 11 \text { injuries, and a direct economic loss of over } 7.2 \text { million CNY. }\end{array}$ \\
\hline 2 & $\begin{array}{l}\text { On } 20 \text { August 2012, Xu was driving a minibus. He turned right at } 22 \mathrm{~km}+600 \mathrm{~m} \text { on provincial highway } 110 \text { in China. He } \\
\text { crossed the center line and collided with a heavy truck, driven by Diao, travelling in the opposite direction. The incident } \\
\text { resulted in } 12 \text { deaths, } 1 \text { injury, and a direct economic loss of over } 6.0 \text { million CNY. }\end{array}$ \\
\hline 3 & $\begin{array}{l}\text { On } 12 \text { August } 2013, \mathrm{Li} \text { was driving a heavy truck. He crossed the center line and his truck collided with a large bus } \\
\text { travelling in the opposite direction at } 768 \mathrm{~km}+260 \mathrm{~m} \text { on national highway } 312 \text { in China. The incident resulted in } 11 \\
\text { deaths, } 12 \text { injuries, and a direct economic loss of over } 12.6 \text { million CNY. }\end{array}$ \\
\hline 4 & $\begin{array}{l}\text { On } 26 \text { August 2013, Shao was driving a heavy truck. At } 305 \mathrm{~km}+140 \mathrm{~m} \text { on national highway } 310 \text { in China, Shao took } \\
\text { the wrong measures and turned left into the opposite lane when the vehicle in the front suddenly braked. Then, the truck } \\
\text { had a frontal collision with a medium-sized bus driven by Ge. The incident resulted in } 10 \text { deaths, } 5 \text { injuries, and a direct } \\
\text { economic loss of over } 8.1 \text { million CNY. }\end{array}$ \\
\hline 5 & $\begin{array}{l}\text { On } 2 \text { May 2015, Yuan was driving a minibus when he suddenly crashed into the opposite lane. Then, the minibus collided } \\
\text { with the front part of a heavy truck at Jinqi road in China. The incident resulted in } 10 \text { deaths, } 3 \text { injuries, and a direct } \\
\text { economic loss of over } 3.7 \text { million CNY. }\end{array}$ \\
\hline 6 & $\begin{array}{l}\text { On } 13 \text { October } 13 \text { 2016, Zhu was driving a heavy semitrailer, while Yu was driving a three-wheel vehicle in the opposite } \\
\text { direction. Both of them slightly crossed the center line and consequently collided with each other. The incident resulted in } \\
11 \text { deaths and a direct economic loss of over } 3.1 \text { million CNY. }\end{array}$ \\
\hline
\end{tabular}

Note: 1 CNY is approximately 0.1571 USD; direct economic losses only involve property damage.

Table 6. Criteria and sub-criteria for a similarity analysis of the causal factors of TCs

\begin{tabular}{|l|l|l|}
\hline \multicolumn{1}{|c|}{ Criterion } & \multicolumn{1}{|c|}{ Sub-criterion } & \multicolumn{1}{c|}{ Description } \\
\hline \multirow{4}{*}{ Human } & psychological state & fear, excitement, nervousness, sadness \\
\cline { 2 - 3 } & physical condition & being drunk, tired, disabled, sick \\
\cline { 2 - 3 } & driving experience & fatigue driving, driving without a license, running a red light \\
\cline { 2 - 3 } & speed & speeding, normal \\
\hline \multirow{3}{*}{ Readicle } & load & overload, normal \\
\cline { 2 - 3 } & vehicle condition & brake system failure, tire fault, steering wheel failure \\
\cline { 2 - 3 } & road condition & flat, rugged, straight, sharp bend \\
\cline { 2 - 3 } & road line & complete, fuzzy, missing \\
\cline { 2 - 3 } & road facilities & traffic signs, traffic lights, traffic guardrail \\
\hline \multirow{3}{*}{ Environment } & weather & sunny, rainy, snowy, foggy, gloomy \\
\cline { 2 - 3 } & visibility & good, poor \\
\cline { 2 - 3 } & time & 24-h clock: e.g., "16 clock" refers to the period from16:00 to 16:59 \\
\hline Management & safety management & driver is responsible for daily cleaning, repair, and other maintenance \\
\cline { 2 - 3 } & traffic regulation & traffic sector is responsible for vehicle supervision and driver management \\
\hline
\end{tabular}

"» the condition of an external factor can reflect a flaw of the internal factor: for instance, a defect in a safety facility (e.g., no traffic lights) indicates a road safety management deficiency.

Through the above analysis, the TC criteria in this study were set as five factors: human, vehicle, road, environment, and management. The sub-criteria of TCs were determined in terms of the respective criteria, as shown in Table 6.

Figure 5 illustrates the scheme of the AHP-S hierarchy model used in this study. In this model, the goal, criteria, sub-criteria, similar elements, similar units, and degree of similarity between TCs are defined and divided into specified groups. All of them are put into the cor-

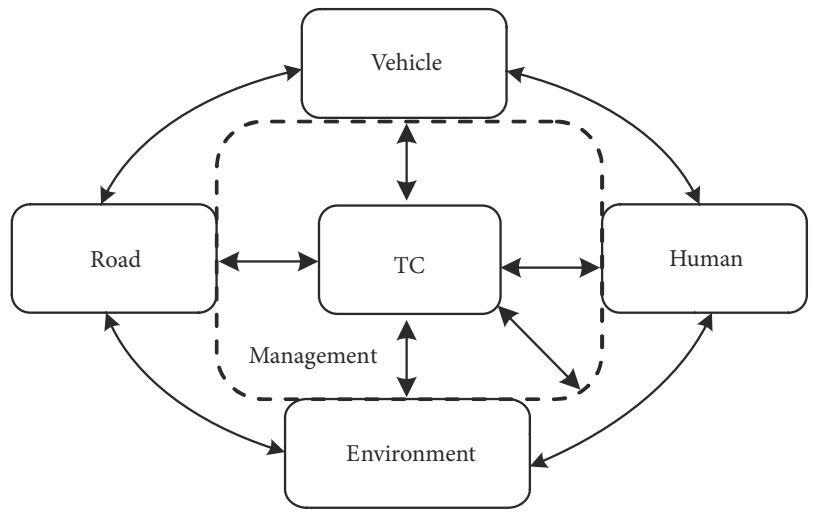

Figure 4. Causal factors of TCs 
rect hierarchical order, and then the connection between them is proposed (Fabjanowicz et al. 2018). Specifically, the goal is connected to each of the criteria; each criterion is linked with sub-criteria; each sub-criterion is connected to a similar element; each similar element is linked with a similar unit, and a similar unit is connected to the degree of similarity between two TC cases.

\subsection{Similar elements and similar units of the causal factors of TCs}

According to the criteria and sub-criteria (Table 6), the six cases were investigated to examine the degree of similarity between the causal factors of TCs. The causal factors of these cases are shown in Table 7. This paper took case 6 as

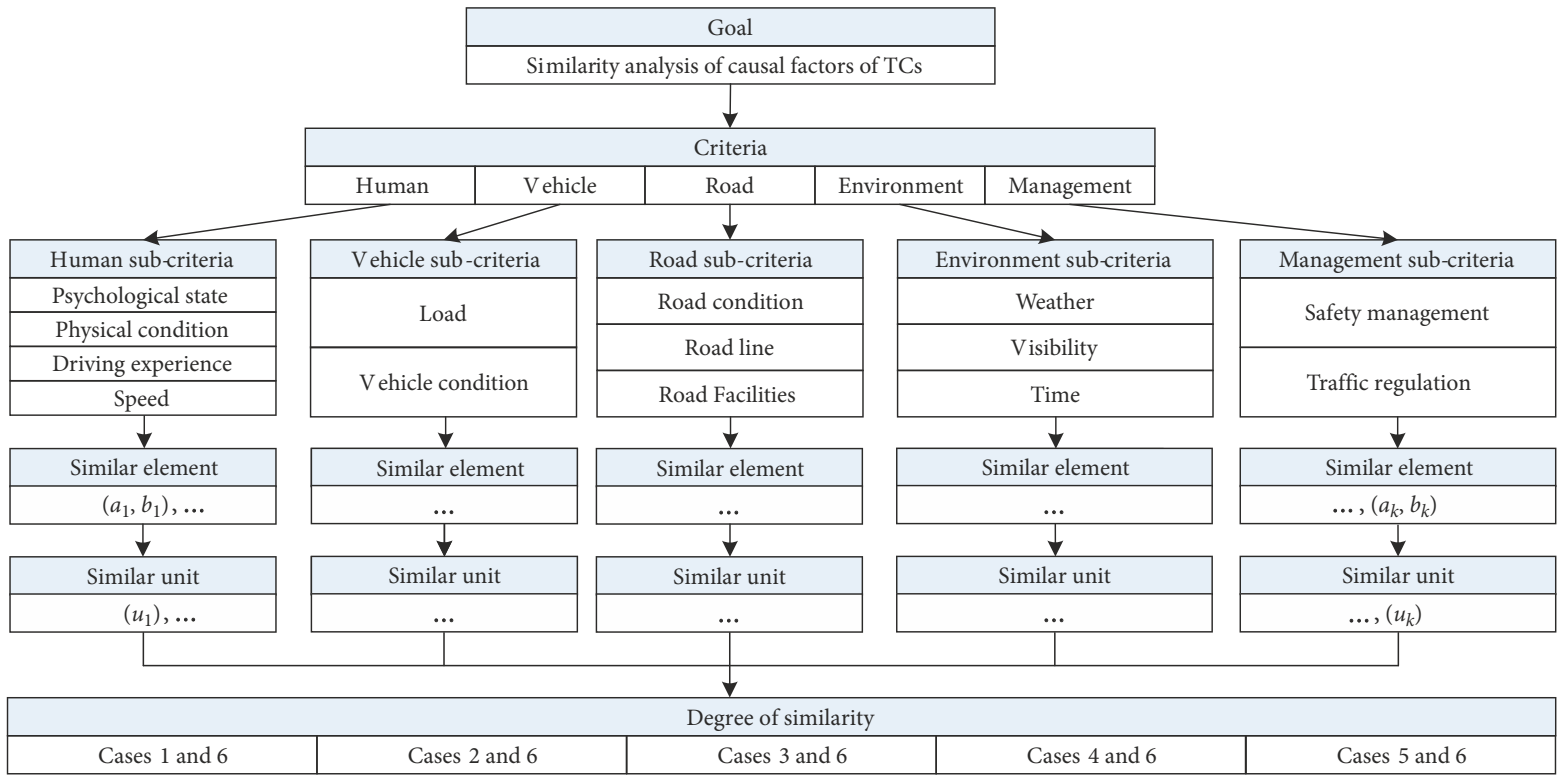

Figure 5. Hierarchical structure of the AHP-S model used for the similarity analysis of the causal factors of TCs

Table 7. Causal factors of six TC cases

\begin{tabular}{|c|c|c|c|c|c|c|c|c|c|c|}
\hline \multirow[b]{2}{*}{ Case } & \multicolumn{6}{|c|}{ Human sub-criteria } & \multicolumn{4}{|c|}{ Vehicle sub-criteria } \\
\hline & $\begin{array}{l}\text { psychological } \\
\text { state }\end{array}$ & $\begin{array}{l}\text { physical } \\
\text { condition }\end{array}$ & \multicolumn{3}{|c|}{ driving experience } & speed & \multicolumn{2}{|c|}{ load } & \multicolumn{2}{|c|}{ vehicle condition } \\
\hline \multirow[t]{2}{*}{1} & normal & abnormal & \multicolumn{3}{|c|}{$\begin{array}{c}\text { illegal operation, many traffic } \\
\text { tickets }\end{array}$} & speeding & \multicolumn{2}{|c|}{ serious overload } & \multicolumn{2}{|c|}{ brake problems } \\
\hline & normal & normal & \multicolumn{3}{|c|}{ normal } & normal & \multicolumn{2}{|c|}{ overload } & \multicolumn{2}{|r|}{ normal } \\
\hline \multirow{2}{*}{2} & normal & normal & \multicolumn{3}{|c|}{ violation } & speeding & \multicolumn{2}{|c|}{ overload } & \multicolumn{2}{|r|}{ normal } \\
\hline & normal & normal & \multicolumn{3}{|c|}{ normal } & speeding & \multicolumn{2}{|c|}{ serious overload } & \multicolumn{2}{|r|}{ normal } \\
\hline \multirow{2}{*}{3} & normal & fatigued & \multicolumn{3}{|c|}{ violation, illegal operation } & speeding & \multicolumn{2}{|c|}{ normal } & \multicolumn{2}{|c|}{ brake problems } \\
\hline & normal & normal & \multicolumn{3}{|c|}{ one traffic ticket } & normal & \multicolumn{2}{|c|}{ normal } & & normal \\
\hline 4 & normal & normal & two traffi & $\begin{array}{l}\text { ickets, } \\
\text { aking }\end{array}$ & proper & normal & serious & verload & & normal \\
\hline & normal & fatigued & illeg & opera & & normal & nor & nal & & normal \\
\hline & normal & fatigued & & ormal & & speeding & over & oad & & t wheels failure \\
\hline 5 & normal & normal & one tra & $\begin{array}{l}\text { ticket } \\
\text { ratior }\end{array}$ & & speeding & nor & nal & & normal \\
\hline & normal & normal & violation & legal c & cation & speeding & serious & verload & & normal \\
\hline 6 & normal & normal & violation, & $\begin{array}{l}\text { riving } \\
\text { cense }\end{array}$ & hout a & normal & nor & & & normal \\
\hline & & ad sub-criteri & & & Environ & sub-crite & & Man & eme & t sub-criteria \\
\hline Case & $\begin{array}{c}\text { road } \\
\text { condition }\end{array}$ & road line & road facilities & time & weath & & & $\begin{array}{r}\text { safe } \\
\text { manag }\end{array}$ & & $\begin{array}{c}\text { traffic } \\
\text { supervision }\end{array}$ \\
\hline 1 & flat road & complete & complete & 14 & overc & clear li & of sight & impe & & insufficient \\
\hline 2 & gentle slope & complete & $\begin{array}{l}\text { no sharp turn } \\
\text { sign }\end{array}$ & 12 & heavy & poor & bility & impe & & insufficient \\
\hline 3 & flat road & complete & complete & 16 & sunn & clear li & of sight & impe & & insufficient \\
\hline 4 & flat road & complete & complete & 16 & sunn & clear li & of sight & impe & & insufficient \\
\hline 5 & gentle slope & fuzzy & incomplete & 1 & overc & $\begin{array}{r}\text { street lig } \\
\text { vi }\end{array}$ & $\begin{array}{l}\text { and poor } \\
\text { lity }\end{array}$ & $i m$ & & insufficient \\
\hline 6 & long slope & complete & complete & 18 & sunn & clear li & of sight & impe & & insufficient \\
\hline
\end{tabular}

Note: The items in italic style represents the incident-causing factors of cases 1 to 6. 
the central study subject for the similarity analysis of the causal factors of TCs; this case was compared with each of the other cases separately. Taking case 1 and case 6 as an example, they were compared from the five perspectives: human, vehicle, road, environment, and management (Table 7). It was assumed that the similar elements of case 1 is recorded as $a_{k}$ and $b_{k}$ of case 6. A similar unit $u_{k}$ was formed when $a_{k}$ is similar to $b_{k}$. As shown in Table 7, cases 1 and 6 include similar elements, such as violation and illegal operation; thus, violation and illegal operation can form a similar unit (i.e., $u_{1}$ ), recorded as " $u_{1}=$ violation and illegal operation". Following the same method, we recorded " $u_{2}=$ speeding", " $u_{3}=$ overload", " $u_{4}=$ imperfect safety management system", and " $u_{5}=$ insufficient traffic supervision". The values of a similar unit $q_{i}$ between cases 1 and 6 were computed by the similarity method and recorded as $q_{i}=\left(q_{1}, q_{2}, q_{3}, q_{4}, q_{5}\right)$. Following the above steps, the similar units between case 6 and cases 2 to 5 , respectively, were analysed separately. The similar units between case 6 and cases 1 to 5 are summarized in Table 8 .

\subsection{Degree of similarity between the causal factors of TCs}

Cases 1 and 6 were taken as examples to calculate the degree of similarity between the causal factors of TCs using the AHP-S method. The main steps of the calculation were as follows.

\subsubsection{The relative weight $w_{i}$ of the causal factors of TCs}

According to the statistical results of crash reports, most collisions are caused by human factors rather than by vehicle defects. For example, Lum and Reagan (1995) found that $93 \%$ of collisions are related to human factors, and Chen et al. (2004) found that $89.95 \%$ of collisions are caused by human factors. From the perspective of collision avoidance, human factors have a higher weighted value than vehicle factors. Excessive speed is a leading risk factor on the road, and most drivers determine their speed by observing their surroundings (Matírnez et al. 2013). Speeding is also considered as a human factor. As $u_{1}$ involves two risk factors, we reasoned that compared to $u_{2}$, the intensity of $u_{1}$ falls in between equal importance and moderate importance, namely $S_{12}=2$ and $S_{21}=1 / 2$. In addition, compared to $u_{3}$, the intensity of $u_{2}$ falls in between equal importance and moderate importance, meaning $S_{23}=2, S_{32}=1 / 2, S_{13}=3$, and $S_{31}=1 / 3$.

Moreover, the human, vehicle, road, and environment risk prevention factors are tightly related to the management system factor. In terms of collision avoidance, management factors have a higher weighted value than human factors. As $u_{4}$ and $u_{5}$ are considered as management factors, we reasoned that $u_{4}$ is equally as important as $u_{5}$, namely $S_{45}=1$ and $S_{54}=1$. In addition, we reasoned that $u_{4}$ is moderately more important than $u_{2}$, meaning $S_{24}=$ $1 / 3, S_{42}=3, S_{25}=1 / 3, S_{52}=3, S_{14}=1 / 2, S_{41}=2, S_{15}=$ $1 / 2$, and $S_{51}=2$.
Table 8. The similar units of the five groups

\begin{tabular}{|c|l|}
\hline \multicolumn{1}{|c|}{ Grouping } & \multicolumn{1}{|c|}{ Similar units } \\
\hline Cases 1 and 6 & $u_{1}=$ violation and illegal operation; \\
& $u_{2}=$ speeding; \\
& $u_{3}=$ overload; \\
& $u_{4}=$ imperfect safety management system; \\
& $u_{5}=$ insufficient traffic supervision \\
\hline Cases 2 and 6 & $u_{1}=$ violation; \\
& $u_{2}=$ speeding; \\
& $u_{3}=$ overload; \\
& $u_{4}=$ imperfect safety management system; \\
& $u_{5}=$ insufficient traffic supervision \\
\hline Cases 3 and 6 & $u_{1}=$ violation and illegal operation; \\
& $u_{2}=$ speeding; \\
& $u_{3}=$ imperfect safety management system; \\
& $u_{4}=$ insufficient traffic supervision \\
\hline Cases 4 and 6 & $u_{1}=$ violation and illegal operation; \\
& $u_{2}=$ overload; \\
& $u_{3}=$ imperfect safety management system; \\
& $u_{4}=$ insufficient traffic supervision \\
\hline Cases 5 and 6 & $u_{1}=$ violation and illegal operation; \\
& $u_{2}=$ speeding; \\
& $u_{3}=$ overload; \\
& $u_{4}=$ imperfect safety management system; \\
& $u_{5}=$ insufficient traffic supervision \\
\hline
\end{tabular}

Table 9. Pair-wise comparison matrix of similar units of the causal factors of TCs

\begin{tabular}{|c:ccccc|}
\hline$S$ & $u_{1}$ & $u_{2}$ & $u_{3}$ & $u_{4}$ & $u_{5}$ \\
\hdashline$u_{1}$ & 1 & 2 & 3 & $1 / 2$ & $1 / 2$ \\
$u_{2}$ & $1 / 2$ & 1 & 2 & $1 / 3$ & $1 / 3$ \\
$u_{3}$ & $1 / 3$ & $1 / 2$ & 1 & $1 / 4$ & $1 / 4$ \\
$u_{4}$ & 2 & 3 & 4 & 1 & 1 \\
$u_{5}$ & 2 & 3 & 4 & 1 & 1 \\
\hline
\end{tabular}

From what has been discussed above, we reasoned that compared to $u_{3}$, the intensity of $u_{4}$ falls in between moderate importance and essential importance, namely $S_{34}=$ $1 / 4, S_{43}=4, S_{35}=1 / 4$, and $S_{53}=4$. Finally, we established a pair-wise comparison matrix (Table 9).

There exist 7 and 5 similar elements in cases 1 and 6, accordingly, and 5 similar units of these two cases were formed (Table 8): i.e., $m=7, n=5, k=5, R I=1.12$. The data (i.e., Table 9, $k$, and RI) were put into Equations (3)(6) to calculate the relative weight $w_{i}$, as follows:

$$
w_{i}=(0.1841,0.11,0.0687,0.3186,0.3186)^{T} .
$$

The CR was calculated as follows:

$$
C R=0.0068<0.1 \text {. }
$$

Consequently, the evaluation within the matrix was acceptable.

\subsubsection{The values of the similar unit $q_{i}$ of the causal factors of TCs}

The values of the similar unit $q_{i}$ were calculated as follows using the similarity method:

$$
q_{i}=(0.4,0.7,0.5,0.8,0.8) .
$$




\subsubsection{The degree of similarity between the causal factors of TCs}

$m, n, k, q_{i}$, and $w_{i}$ were put into Equation (8), and the degree of similarity between cases 1 and 6 was calculated as follows:

$$
\begin{aligned}
& Q(1,6)=\frac{5}{7+5-5} \cdot(0.1841 \cdot 0.4+0.11 \cdot 0.7+ \\
& 0.0687 \cdot 0.5+0.3186 \cdot 0.8+0.3186 \cdot 0.8)=49.63 \% .
\end{aligned}
$$

In addition, the degrees of similarity between cases 2 to 5 and case 6 were calculated respectively following the above steps; the results were as follows:

$$
\begin{aligned}
& Q(2,6)=41.68 \% ; \\
& Q(3,6)=40.76 \% ; \\
& Q(4,6)=46.11 \% ; \\
& Q(5,6)=33.98 \% .
\end{aligned}
$$

\section{Discussion of results}

Our analysis of the casual factors of six TC cases clearly shows that every case included causes such as driver violations, speeding, and overload. According to the investigation reports, driver factors, such as crossing the center line, illegal overtaking, speeding, and driver fatigue, are the direct causes of collisions. In addition, vehicle factors, such as overload and brake problems, increase the severity of collisions (Vorko-Jović et al. 2006).

Due to knowledge gaps or biases, decision makers may ignore crucial information in the investigation and analysis of incidents. Identifying the similar units of the causal factors of TCs will help decision makers to find evidencebased information for preventing the occurrence of similar incidents. For instance, case 1 happened in 2012, which was earlier than case 6 happening in 2016. Case 6 could have been avoided if decision makers had learnt lessons from case 1 in terms of the human, vehicle, road, environ- ment, and management related causal factors and taken appropriate actions to control similar conditions.

The ranking of the degrees of similarity between cases 1 to 5 and case 6 can be described as follows: case $1>$ case 4 $>$ case $2>$ case $3>$ case 5 . Compared to the other four cases, case 1 provides the best evidence available for analysing the causal factors of case 6 . Due to the degree of similarity between case 1 and case 6 being scored 0.4963 , it can be used with larger samples of TCs to find other high-similarity cases for analysing case 6 . In the future, this method can be developed into computer software to analyse the degree of similarity between different collisions, which can save time and increase efficiency for safety practitioners in terms of incident analysis. If combined with big data technology, this method can automatically analyse TC information sources and provide the best evidence for road safety policy making.

The management factor of traffic safety defects was a common problem among the six TC cases. On the basis of the similarity analysis between cases 1 to 5 and case 6 , traffic safety improvements could be carried out using the " $6 \mathrm{E}$ " measures - engineering, education, enactment, enforcement, emergency, and evaluation - Gao et al. (2015), (Table 10). The aim is to improve road traffic safety practices in order to avoid the occurrence of similar collisions and to save lives.

It is worth noting that more specific and multifaceted indicators related to traffic safety should be further investigated in order to provide more comprehensive evidence for safety practices. In practical application, the analysis can be performed by changing indicator weights according to the actual situation. In order to enable more effective use of the similarity analysis method, more detailed information related to collision incidents should be col-

\begin{tabular}{|c|c|}
\hline Perspectives & Explanations \\
\hline Engineering & $\begin{array}{l}\text { "» establish an institution for the training and examination of drivers; } \\
\text { "» design automatic alarm devices for speeding or overload; } \\
\text { "» develop devices for monitoring drivers' violation behaviour }\end{array}$ \\
\hline Education & $\begin{array}{l}\text { "» educate drivers to learn the laws and regulations related to traffic safety; } \\
\text { "» driving simulations to correct unsafe behaviour; } \\
\text { "» build up periodic training system. }\end{array}$ \\
\hline Enactment & $\begin{array}{l}\text { "» revise and perfect laws related to traffic safety; } \\
\text { "» establish qualification permit systems for freight drivers; } \\
\text { "» standardize the design of traffic safety facilities }\end{array}$ \\
\hline Enforcement & $\begin{array}{l}\text { "» strengthen monitoring in collision-prone sections; } \\
\text { "» increase penalties for traffic violations; } \\
\text { "» strengthen early warnings of poor environment }\end{array}$ \\
\hline Emergency & $\begin{array}{l}\text { "» formulate emergency schemes; } \\
\text { "» develop emergency supplies equipment; } \\
\text { "» establish "green passages" for emergencies. }\end{array}$ \\
\hline Evaluation & $\begin{array}{l}\text { "» evaluate degree of safety of road facilities; } \\
\text { "» construct electronic evaluation system for driving behaviour and safety education }\end{array}$ \\
\hline
\end{tabular}
lated. Due to the limits of manual computation, this study only selected six cases to compute the degree of similarity between the causal factors of TCs, which may mean that the measurement results are not accurate enough.

Table 10. “6E” measures for traffic safety improvement 


\section{Conclusions}

In order to use existing information resources on TCs, this study developed a similarity analysis method, the AHP-S method, for quantitatively analysing the degree of similarity between the causal factors of collisions that combines the advantages of the AHP and similarity theory. The core of the method is to identify the similar elements and similar units of the causal factors of TCs according to the criteria and sub-criteria. It provides evidence-based practice support for collision investigation and analysis.

Using six TC cases in China as examples, the degrees of similarity between the causal factors of TCs were calculated using the AHP-S method. This study took case 6 as the central study subject, and the calculation results showed that the degrees of similarity between cases 1,2 , 3,4 , and 5 and case 6 were 49.63, 41.68, 40.76, 46.11, and $33.98 \%$, respectively. The ranking of the similarity of the five cases can be presented as follows: case $1>$ case $4>$ case $2>$ case $3>$ case 5 ; that is, compared to the other four cases, case 1 provides the best evidence available for the analysis of the causal factors of case 6. With a larger collision sample, the AHP-S method could find other highsimilarity cases for analysing case 6 . In doing so, it would supplement the available safety insights gained from the literature or reports.

Moreover, the results of the similarity analysis of collisions were further discussed and the "6E" (engineering, education, enactment, enforcement, emergency, and evaluation) traffic safety improvement measures were put forward. Overall, this study can help decision makers discover targeted measures for traffic risk prevention, and it has reference value for investigating similar evidence in other fields, such as mine safety, construction safety, and chemical safety, etc.

\section{Acknowledgements}

The authors would like to thank National Natural Science Foundation of China (Grant No 51534008) for supporting this research.

\section{Funding}

This work was supported by the National Natural Science Foundation of China (Grant No 51534008).

\section{Author contributions}

Liangguo Kang was responsible for manuscript writing and editing, data analysis, content planning.

Shuli Zhang was responsible for literature search, data collection and analysis, content planning.

Chao $W u$ was responsible for manuscript editing, content planning and research guidance.

\section{Disclosure statement}

Authors do not have any competing financial, professional, or personal interests from other parties.

\section{References}

Andersson, A. K.; Chapman, L. 2011. The impact of climate change on winter road maintenance and traffic accidents in West Midlands, UK, Accident Analysis \& Prevention 43(1): 284-289. https://doi.org/10.1016/j.aap.2010.08.025

Calabrese, A.; Costa, R.; Levialdi, N.; Menichini, T. 2016. A fuzzy analytic hierarchy process method to support materiality assessment in sustainability reporting, Journal of Cleaner Production 121: 248-264.

https://doi.org/10.1016/j.jclepro.2015.12.005

Chen, F.; Wang, J.; Deng, Y. 2015. Road safety risk evaluation by means of improved entropy TOPSIS-RSR, Safety Science 79: 39-54. https://doi.org/10.1016/j.ssci.2015.05.006

Chen, F.; Wu, J.; Chen, X.; Wang, J.; Wang, D. 2016. Benchmarking road safety performance: Identifying a meaningful reference (best-in-class), Accident Analysis \& Prevention 86: 76-89. https://doi.org/10.1016/j.aap.2015.10.018

Chen, M.; Yuan, X.; Pan, M.; Xie, Z. 2004. Discussion on preventive measures for road traffic accidents from statistic analysis and comparison, China Safety Science Journal (8): 59-63. (in Chinese).

Cvitanić, D.; Vukoje, B. 2018. Detection and analysis of hazardous locations on roads: a case study of the Croatian motorway A1, Transport 33(2): 418-428. https://doi.org/10.3846/16484142.2016.1259180

Duleba, S. 2019. An AHP-ISM approach for considering public preferences in a public transport development decision, Transport 34(6): 662-671. https://doi.org/10.3846/transport.2019.9080

Fabjanowicz, M.; Bystrzanowska, M.; Namieśnik, J.; Tobiszewski, M.; Płotka-Wasylka, J. 2018. An analytical hierarchy process for selection of the optimal procedure for resveratrol determination in wine samples, Microchemical Journal 142: 126-134. https://doi.org/10.1016/j.microc.2018.06.028

Farooq, D.; Moslem, S.; Duleba, S. 2019. Evaluation of driver behavior criteria for evolution of sustainable traffic safety, Sustainability 11(11): 3142. https://doi.org/10.3390/su11113142

Fernandes, R.; Hatfield, J.; Soames Job, R. F. 2010. A systematic investigation of the differential predictors for speeding, drink-driving, driving while fatigued, and not wearing a seat belt, among young drivers, Transportation Research Part F: Traffic Psychology and Behaviour 13(3): 179-196.

https://doi.org/10.1016/j.trf.2010.04.007

Gao, Y.; Dong, X.; Tian, F. 2015. Present situation analysis on highway traffic safety and management countermeasures, Journal of Safety Science and Technology (10): 110-115. (in Chinese).

Goel, G.; Sachdeva, S. N. 2016. Analysis of road accidents on $\mathrm{NH}-1$ between RD $98 \mathrm{~km}$ to $148 \mathrm{~km}$, Perspectives in Science 8: 392-394. https://doi.org/10.1016/j.pisc.2016.04.086

Goh, Y. M.; Ubeynarayana, C. U. 2017. Construction accident narrative classification: an evaluation of text mining techniques, Accident Analysis \& Prevention 108: 122-130. https://doi.org/10.1016/j.aap.2017.08.026

Herva, M.; Roca, E. 2013. Review of combined approaches and multi-criteria analysis for corporate environmental evaluation, Journal of Cleaner Production 39: 355-371. https://doi.org/10.1016/j.jclepro.2012.07.058

Ho, W.; Ma, X. 2018. The state-of-the-art integrations and applications of the analytic hierarchy process, European Journal of Operational Research 267(2): 399-414. https://doi.org/10.1016/j.ejor.2017.09.007 
Hu, L.; Li, Y. 2014. Impact analysis on typical transport facilities to causes of road traffic accidents, Journal of Wuhan University of Technology (Transportation Science \& Engineering) (1): 98-102. (in Chinese).

Hruška, R.; Průša, P.; Babić, D. 2014. The use of AHP method for selection of supplier, Transport 29(2): 195-203. https://doi.org/10.3846/16484142.2014.930928

Ilbahar, E.; Karasan, A.; Cebi, S.; Kahraman, C. 2018. A novel approach to risk assessment for occupational health and safety using Pythagorean fuzzy AHP \& fuzzy inference system, Safety Science 103: 124-136.

https://doi.org/10.1016/j.ssci.2017.10.025

Jia, N.; Wu, C.; Huang, L.; Wang, B. 2016. Methodology of similarity safety systematics research, China Safety Science Journal (6): 30-35. (in Chinese).

Li, S.-C.; Xiao, L. 2016a. Statistics of industrial accidents in China during the period from January to February in 2016, Journal of Safety and Environment (2): 395-396. (in Chinese).

Li, S.-C.; Xiao, L. 2016b. Statistics of industrial accidents in China during the period from March to April in 2016, Journal of Safety and Environment (3): 395-396. (in Chinese).

Li, S.-C.; Xiao, L. 2016c. Statistics of industrial accidents in China during the period from May to June in 2016, Journal of Safety and Environment (4): 395-396. (in Chinese).

Li, S.-C.; Xiao, L. 2016d. Statistics of industrial accidents in China during the period from July to August in 2016, Journal of Safety and Environment (5): 395-396. (in Chinese).

Li, S.-C.; Xiao, L. 2016e. Statistics of industrial accidents in China during the period from September to October in 2016, Journal of Safety and Environment 16(6): 395-396. (in Chinese).

Li, S.-C.; Xiao, L. 2017. Statistics of industrial accidents in China during the period from November to December in 2016, Journal of Safety and Environment 17(1): 395-396. (in Chinese).

Llopis-Castelló, D.; Camacho-Torregrosa, F. J.; García, A. 2018. Development of a global inertial consistency model to assess road safety on Spanish two-lane rural roads, Accident Analysis \& Prevention 119: 138-148. https://doi.org/10.1016/j.aap.2018.07.018

Lum, H.; Reagan, J. A. 1995. Interactive highway safety design model: accident predictive module, Public Roads 58(3): 14-17.

MacLean, A. W.; Davies, D. R. T.; Thiele, K. 2003. The hazards and prevention of driving while sleepy, Sleep Medicine Reviews 7(6): 507-521. https://doi.org/10.1016/S1087-0792(03)90004-9

Matírnez, A.; Mántaras, D. A.; Luque, P. 2013. Reducing posted speed and perceptual countermeasures to improve safety in road stretches with a high concentration of accidents, Safety Science 60: 160-168. https://doi.org/10.1016/j.ssci.2013.07.003

Nævestad, T.-O.; Phillips, R. O.; Elvebakk, B. 2015. Traffic accidents triggered by drivers at work - a survey and analysis of contributing factors, Transportation Research Part F: Traffic Psychology and Behaviour 34: 94-107.

https://doi.org/10.1016/j.trf.2015.07.024

Pérez, J. A.; Gonçalves, G. R.; Rangel, J. M. G.; Ortega, P. F. 2019. Accuracy and effectiveness of orthophotos obtained from low cost UASs video imagery for traffic accident scenes documentation, Advances in Engineering Software 132: 47-54. https://doi.org/10.1016/j.advengsoft.2019.03.010

Podvezko, V.; Sivilevičius, H. 2013. The use of AHP and rank correlation methods for determining the significance of the interaction between the elements of a transport system having a strong influence on traffic safety, Transport 28(4): 389403. https://doi.org/10.3846/16484142.2013.866980
Prentkovskis, O.; Sokolovskij, E.; Bartulis, V. 2010. Investigating traffic accidents: a collision of two motor vehicles, Transport 25(2): 105-115. https://doi.org/10.3846/transport.2010.14

Saaty, T. L. 2008. Decision making with the analytic hierarchy process, International Journal of Services Sciences 1(1): 83-98. https://doi.org/10.1504/IJSSCI.2008.017590

Sarkar, C.; Webster, C.; Kumari, S. 2018. Street morphology and severity of road casualties: a 5-year study of Greater London, International Journal of Sustainable Transportation 12(7): 510-525. https://doi.org/10.1080/15568318.2017.1402972

SAWS. 2016. Accident Investigation Reports. State Administration of Work Safety (SAWS), China. Available from Internet: http://english.www.gov.cn/state_council/2014/09/09/content_281474986284037.htm (in Chinese).

SC PRC. 2007. Report on Work Accident and Regulations of Investigation and Treatment. The State Council, The People's Republic of China (SC PRC). Available from Internet: http://english.www.gov.cn (in Chinese).

Stević, Ž.; Vasiljević, M.; Puška, A.; Tanackov, I.; Junevičius, R.; Vesković, S. 2019. Evaluation of suppliers under uncertainty: a multiphase approach based on fuzzy AHP and fuzzy EDAS, Transport 34(1): 52-66.

https://doi.org/10.3846/transport.2019.7275

Sze, N. N.; Song, Z. 2019. Factors contributing to injury severity in work zone related crashes in New Zealand, International Journal of Sustainable Transportation 13(2): 148-154. https://doi.org/10.1080/15568318.2018.1452083

Vorko-Jović, A.; Kern, J.; Biloglav, Z. 2006. Risk factors in urban road traffic accidents, Journal of Safety Research 37(1): 93-98. https://doi.org/10.1016/j.jsr.2005.08.009

Wang, B.; Wu, C.; Shi, B.; Huang, L. 2017. Evidence-based safety (EBS) management: a new approach to teaching the practice of safety management (SM), Journal of Safety Research 63: 21-28. https://doi.org/10.1016/j.jsr.2017.08.012

Wu, C.; Jia, N. 2016. Establishment of similarity safety systematics, Systems Engineering-Theory \& Practice (5): 1354-1360. (in Chinese).

Wu, J.; Subramanian, R.; Craig, M.; Starnes, M.; Longthorne, A. 2013. The effect of earlier or automatic collision notification on traffic mortality by survival analysis, Traffic Injury Prevention 14: S50-S57. https://doi.org/10.1080/15389588.2013.799279

Zhao, J.; Deng, W. 2015. The use of Bayesian network in analysis of urban intersection crashes in China, Transport 30(4): 411-420. https://doi.org/10.3846/16484142.2013.816365

Zhou, P.; Ang, B. W. 2009. Comparing MCDA aggregation methods in constructing composite indicators using the ShannonSpearman measure, Social Indicators Research 94(1): 83-96. https://doi.org/10.1007/s11205-008-9338-0 